\title{
INTERCALAÇÃO, METADISCURSO E AUTORIA: POR UMA ANÁLISE TEXTUAL-DISCURSIVA DA INTERPOSIÇÃO NA ESCRITA ${ }^{(*)}$
}

\section{Juliene Barros Universidade Estadual de Campinas}

\section{Introduzindo o tema}

Minhas considerações neste artigo estão circunscritas a alguns fenômenos de uso da linguagem, conhecidos como inserções. digressões e notas de rodapé. Proponho uma recategorização conceitual e, assim, uma renomeação genérica - intercalação - para os três termos, analisando textos escritos de diversos gêneros do discurso acadêmico. Adoto uma perspectiva de interface, pondo a serviço de um mesmo interesse postulados centrais da Lingüística Textual (LT), especialmente os de coerência, coesão, relevância e riprico discursivo, e também conceitos da Análise do Discurso (AD), nomeadamente os de metadiscurso e autoria. Antes, porém, retomo abordagens tradicionais, para justificar a hipótese de que, mesmo numa fundamentação enunciativa, algumas análises conservam rescpuicios da visão fragmentária e dispersiva pela qual as intercalações se definiam na retórica e na gramática, daí a necessidade ki retomar a questão.

\section{Abrindo um parêntese para a tradição}

Já nas especulações aristotélicas sobre a Retórica (Molsés, 1974), pode-se ver a referência a digressões e excursos, bem como a conceituação de figuras de retórica, responsáveis, rispectivamente, pela interpolação de assunto mais estranho (e, portanto, desviante), ou menos estranho àquele que está sendo tratado no momento. De uma perspectiva diferente, mas com um olhar scmelhante, na chamada Nova Retórica ou Retórica da Leitura,

I Ima grata notinha para não esquecer as valiosas contribuições de Renira I isboa, Roberto Sarmento e Francisca Santos, nos momentos iniciais dista pesquisa. 
Barthes (apud Plebe e Emanuele, 1992) usa o termo interclusão para dar conta do encaixe parentético de espaços, palavras, frases ou episódios no interior de uma frase ou contexto de frases, o que, da ótica do leitor, causa um vazio de espera e de conteúdo a ser preenchido retrospectivamente.

Evidências desse interesse pelo assunto ao longo do tempo podem-se ver também em muitos estudos gramaticais, que, sob a ótica da tradição lógico-formal, observam a boa formação de orações e períodos e, não raro, advertem quanto ao uso de digressões e inserções - chamadas orações intercaladas, justapostas, interferentes etc. - que, por não se relacionarem com o período (como ocorre com as subordinadas e coordenadas) tendem a dificultar a clareza e a compreensão linear das idéias. O mesmo pode ser visto da ótica de alguns estudos de base descritiva (Fulgêncio e Liberato, 1996) os quais, abordando problemas de escrita e leitura, tratam as inserçóes como encaixes que tornam as sentenças dificeis de serem compreendidas, mesmo quando se enaltece - nas duas perspectivas as funções semânticas e o valor informativo dos incisos.

Pois bem, conquanto sejam claras as diferenças entre todos esses estudos, não há como deixar de ser visto que, quer se trate de estudos de texto, quer se trate de estudos gramaticais, tradicionais ou modernos, há uma semelhança no tratamento dado aos fenômenos, no que diz respeito à tendência fragmentária e ao efeito dispersivo que acompanha as digressões e inserções e também, em certa medida, as notas de rodapé (estas sequer devem constar no continuum textual, conforme muitos manuais de redação, científica ou não). Por um olhar retrospectivo, podem-se extrair desses estudos dois consensos, entre si contraditórios: primeiro, há em todos eles a definição do fenômeno como segmento não pertinente, digressivo, justaposto (quando muito); segundo, há igualmente em todos eles o reconhecimento da recorrência e da importância do fenômeno, dado o valor informativo.

Essa forma de pensar, que permite ver uma nítida incongruência entre sintaxe e semântica, denuncia um modo de conceber a linguagem - instrumento, de comunicação ou de representação lógico-formal - em que se vêem apelos à linearidade e à clareza. Isso justifica o tratamento do fenômeno ao longo da tradição, ao tempo en que serve para separar esses estudos das atuais abordagens de texto. Os estudos modernos adotam uma concepção de 
lınguagem sociointeracional, a qual será decisiva para a abordagem de muitos aspectos da produção/compreensão textual que não se viam contemplados naquelas visões sistemáticas. Com as intercalações, há um avanço paulatino, pois as primeiras análises carregam ainda resquicios das abordagens anteriores. Vejamos.

\section{Intercalando a Lingüística Textual}

Com a Lingüística Textual, tem-se o significativo avanço de conceber os fenômenos em foco sob a ótica da interação e de relacioná-los à coerência dos textos, de forma a ser assumido o importante postulado segundo o qual as intercalações (digressões e inserções, pois não são vistos estudos especificos sobre as notas) são bem vindas aos textos, não prejudicam e ajudam a constituir a coerência.

Apesar disso, o apelo à unidade tópica, que é feito pelo princípio da relevância, a ênfase no fato de que as intercalações devem ser marcadas, e também as próprias formas de designação do fenômeno deixaram, tão implícita quanto evidente, em alguns casos, não a mesma incongruência entre sintaxe e semântica, mas um visível deslocamento das intercalações em relação ao texto. A mudança de perspectiva efetivada não fora suficiente (e nem poderia) para que as intercalações se vissem, já de início, "acomodadas" em meio aos muitos princípios e unidades textuais que serviam como categorias de análise; na verdade, verifica-se, no tratamento desse fenômeno, uma evolução que acompanha, num certo sentido, o próprio avançar conceitual da LT.

No início dos estudos, quando não se tinham tirado as conseqüencias devidas do que deveria significar uma abordagem sociointeracional e considerava-se que a coerência (como a coesão) é uma categoria lingüística apenas, atestável na materialidade lingüística do texto, foi natural o não tratamento ou o estatuto residual atribuído a certos fenômenos mais, digamos, da ordem da enunciação que do enunciado, como as intercalações. (Elas passaram a ser vistas mais tarde, na oralidade).

Mesmo com o claro avanço no sentido de separar coesão de coerência e atribuir a esta última um alcance bem maior do que o lingüístico, parece ter sido vista, nessa abertura, a perda dos limites da unidade de análise e a conseguinte necessidade de critérios para se 
dizer o que fazia a coerência de um texto. Em decorrência, talvez, viuse o apelo (necessário, sem dúvida; em certa medida, porém) ao princípio da relação, como forma de prevenir a dispersão nos textos e garantir a unidade do tópico discursivo. Evidência disso tem-se na elevação da máxima da relevância, de P. Grice (1975), a qual parece ser retomada pelo principio da relevância, em R. Giora (1985) e pela metarregra da relação, em M. Charolles (1997), trabalhos estes que, mesmo inscrevendo-se numa fase posterior dos estudos, excluem, pelo primado da relação, as intercalações (digressivas, sobretudo). Nesse ambiente o fenômeno voltou a ser enfocado, a título de contraexemplo (saibamos), tendo-se em vista a advertência de que os assuntos deveriam ser relacionados ao tópico central e, as digressōes. se houvesse, deveriam ser marcadas, pois isso evitaria que a fragmentação se efetivasse.

Assumido o alargamento do conceito de coerência, começou a configurar-se um tratamento bem mais satisfatório do aspecto em foco. Num pioneiro estudo de Dascal e Katriel (1979), que é base para muitos trabalhos posteriores sobre o fenômeno, os autores deram estatuto de análise à intuição de que as digressões não perturbam a coerência conversacional, e até ajudam a constituí-la. Com isso, os autores instauram postulados decisivos para a reorientação dos conceitos de tópico e relevância.

Mas, para confirmar que, mesmo estudos enunciativos, deixam implícita, ao lado do reconhecimento das funções informativas, uma conotação negativa do fenômeno, devida ao desvio pelo qual ele se define na retórica e na gramática, destaco que os dois autores usam a designação genérica digressão para toda intercalação e, como sub-espécie da digressão, é que há a possibilidade de inserções (digressões baseadas em seqüencias inseridas - as seqüências pergunta/resposta), de modo a ainda enfatizarem a descontinuidade sintática e informacional (é um indício de que a descontinuidade define o fenômeno, antes de serem reconhecidas suas funções).

Outro estudo que deve ser tomado como um dos pilares para a orientação enunciativa das intercalações são os artigos de Jubran (1993 e outros), nos quais a autora aborda, por focos variados, as orações parentéticas. Nesses artigos, pode-se depreender uma configuração bastante ampla, posto que são analisadas as formas de 
identificação, a relação com o tópico, as funções interatıas c outras implicações dos parênteses. Isso, sem dúvida, intensılica o ja mencionado trabalho de "assentamento" das intercalaçòes no texto conversacional - independente de sabermos que são usados criticios de descontinuidade para defini-las.

Além disso, o que me parece um outro resquício da referida visão fragmentária é, inicialmente, o fato de a autora designar as intercalações como parênteses (mas desse e de outros indicios não tratarei agora) e também a reiterada conceituação de um certo tipo de inserção como frase hóspede: (...) Para tanto, tomaremos a primeira modalidade de inserção aqui referida, que é a das frases hóspedes (Jubran, 1993:69). Se tais indícios não configuram um contra-senso em relação aos objetivos da Jubran, carregam, para dentro de sua análise, um discurso anacrônico para uma lingüística enunciativa. A idéia de frase hóspede não me parece muito distinta da de excurso, conforme o tropos aristotélico e, como se sabe, esse tropo, embora diferenciado da digressão por um grau maior de relação com o assunto en pauta, não passa de expediente pronto, anterior e exterior ao discurso.

A última evidência para demonstrar a evolução do tratamento dado às intercalações na LT são trabalhos de Koch, como, por exemplo, Koch (1997). Embora a autora se baseie nos estudos citados, no que respeita ao tratamento das funções enunciativas do fenômeno, faz reflexões que separam seus trabalhos dos anteriores. Isso pode ser visto em, pelo menos, três indícios: Koch contesta o estatuto das quase-digressões, tratadas por Dascal e Katriel (op. cit.) mostrando que, dada a natureza do conteúdo inserido (explicações, alusões...), são desmembramentos naturais do tópico e não desvios; trata de modo diferenciado e em separado digressões e inserções; e (eis um grande avanço), frente à dinamicidade do tópico conversacional e às funções dos fienômenos inseridos, questiona - numa interrogação retórica - se, de fato, existem "digressões".

Tal interrogação - que fora, por vezes, interpretada literalmente e tem recebido críticas indevidas - é, a meu ver, o maior indício de um real engastamento das intercalações na textualidade. Koch não se pergunta se existem digressões, no sentido de interposições, sobreposições, já que discorre longamente sobre isso, revendo funções, ajustando classificações etc; o que a autora parece 
contestar é se tais fenômenos são, realmente, digressões, no sentido de desvio, irrelevância, descontinuidade, enfim.

Concluo, assim, o percurso mencionado no início do subtópico, e o retomo por três afirmações: a LT é o espaço teórico privilegiado para abordar as intercalações, porque elas são fenômenos textuais - com implicações para a coerência e a coesão - e revelam que sua caracterização e seus efeitos não podem ser analisados da perspectiva da frase; com as pesquisas em LT, houve o avanço de concebê-las como algo que não prejudica, mas ajuda a constituir a coerência, notando-se, assim, um progressivo desvencilhar-se da tradição, que as considerava desvios, mesmo quando reconhecia funções isoladas; efetivou-se, com as reflexões sobre as intercalações, uma importante rediscussão a respeito de princípios como a relevância e o tópico discursivo, de modo a poder ser vista, atualmente, uma satisfatória relação do fenômeno com a textualidade.

Mas, há, no mínimo, três questões a serem consideradas: as análises feitas contemplam a conversação e não o texto escrito, de forma que as notas de rodapé, específicas dessa modalidade, não são abordadas; o fenômeno é ainda concebido sob terminologias diversas; as digressões e as inserções são vistas em separado e a ênfase, portanto, é dada em funções específicas e não numa macro-função que lhes revele a natureza comum; conforme respaldadas por fundamentos da cognição e da pragmática, as análises de fala tratam a subjetividade mostrada nas intercalações como muito ligada à intenção do falante, $o$ que, a meu ver, não deixa de existir, em certa medida e em certo nivel, mas que é relativizada pelas condições de produção da escrita sobretudo a acadêmica - razão pela qual prefiro falar em ação.

Por conta desses problemas, proponho uma abordagem do fenômeno no texto escrito. Nessa perspectiva, é possivel enfeixar digressões, inserções e notas de rodapé sob a designação ampla de intercalação, com os possíveis subtipos: digressiva - no nível dos efeitos e não da definição - e não digressiva, por um critério de centração; e presente ou deslocada, por um critério de presença no continum, porque todas elas evidenciam uma mesma natureza metaenunciativa, que as justifica como inclusão - interposição do sujeito - e não como desvios. (Darei exemplos no subtópico seguinte).

Por considerar a metaenunciação como um indício de coerção discursiva e negociação pragmática, simultaneamente, adoto o 
conceito de sujeito tal como tratado por Possenti (1998) (...) um sujeito que age (...), produz uma atividade (...) (p. 43), no interior de subsistemas em processo (p. 38). Tal sujeito produz uma ação condicionada num horizonte de possibilidades. Esse trabalho do sujeito (Bakhtin, 1979) é percebido nas intercalações através da metaenunciação (Authier-Revuz, 1990), tendo este termo em meu trabalho o sentido dado por Maingueneau (1997) - o de metadiscurso.

\section{A propósito da Análise do Discurso}

Ao tratar dos muitos fenômenos que constituem a heterogeneidade enunciativa, Maingueneau (1997) aborda o conceito
de metadiscurso do locutor, o qual serve aos meus propósitos. O autor afirma que a heterogeneidade enunciativa não está ligada unicamente à presença de sujeitos diversos em um mesmo enunciado, ela pode resultar da construção, pelo locutor, de niveis distintos no interior do próprio discurso (p. 93). Em sintese, na atividade metadiscursiva, o "locutor" evidencia tanto sujeitos diversos, quanto níveis distintos de dizer. Sobre isso incidirá minha atenção.

Antes, porém, faço uma breve antecipação, depreendida da observação dos dados: "níveis" e "sujeitos" não são, em todos os casos, instâncias distintas, pois a focalização num outro enunciador. quando interposta numa intercalação, sobrepõe, mesmo rapidamente, um outro nível enunciativo. Do mesmo modo, numa intercalação em que se evidenciem comentários mais ou menos relacionados, pode-se estar, com isso, introduzindo outro ponto de vista, outro sujeito. Não percamos, pois, de vista essa possibilidade de sobreposição das duas atividades.

A título de análise, contudo, e para mostrar como as duas atividades de fato se realizam, irei enfocá-las em separado, fazendo delas categorias analíticas, para catalogar os dados da pesquisa. Trabalharei então com dois tipos de atividade metaenunciativa. nomeadas provisoriamente de mostração do outro e diferenciação de níveis informacionais. Por essas duas atividades, o sujeite condutor da enunciação evidencia a si mesmo ou a outro, em forma de sujcito particular (alguém a quem se atribui o discurso) ou de um discurso mais amplo, sem particularizar posiçōes (uma disciplina. um partido, etc.); da mesma forma, evidenciam-se camadas e propósitus enunciativos distintos, em níveis informacionais que se sobrepoem. 
Observemos três exemplos. Em (1), há o que classifiquei como intercalação não digressiva presente no continuum (juntos os critérios de centração e presença).

(1) (...) Elas nem chegam mesmo a alterar o andamento do tópico em curso, já que visam justamente a clarificar ou corrigir algo, do contrário, poderiam prejudicar a intercompreensão, fazendo, pois, com que a interação progrida de modo desejado. (Dai a possibilidade mesmo de encaixes múltiplos, como evidencia Marcuschi, 1986). (...) (Koch, 1999:89. Negrito e sublinhado nossos, em todas).

Trata-se de uma rápida interposição no corpo do texto, para intercalar um pequeno comentário, corroborando a posição da autora. Observemos que se trata, nesse caso, da referida atividade metaenunciativa de mostração do outro. pela qual a heterogeneidade discursiva, que emerge em forma de ji--111n. é textualizada. Conquanto isso seja óbvio, não custa ratificar que. (m) (1), o propósito enunciativo não é, de forma alguma, digressionar (desviar). Observemos outro caso, com o mesmo subtipo de intercalação não digressiva, desta vez, deslocada do continuum.

(2) A maioria das ciências, observa Saussure, não há dualidade entre diacronia e sincronia: a Astronomia ć um a ciência sincrônica (embora os astros mudem); a Geologia (c uma ciência diacrônica (ainda que possa estudar os estados físicos): a História é sobretudo diacrônica (sucessão de acontecumentos), embora possa deter-se em quadros. (56). (Nota 56: SERIA PRE( ISO) I.EMIBRAR QUE, a partir de Saussure, a própria História descobriu também, a importância das estruturas sincrônicas. Economia, Geologia, Etnografia e História formam atualmente o quadrivium de (iências- piloto). (Barthes, 1964:57).

Mesmo cm posição de rodapé. é ingênuo dizer que se trate de uma digressão. Critérios conhecidos não sustentariam uma tal afirmação. Se pensarmos em relevância semantica, veremos quj̃ unceralmente ligado ao assunto do texto é o conteúdo da intercalação. lli. ayur. a atividade metaenunciatıva de diferenciação de niveis informbicionais, mas isso nào significa desvo de assunto proncipalmente em se tratando de um texto academico. Se apelarmo: para um entro critério como a extensão do segmento interposto. a afirmação não se sustenta igualmente. Alıis. nem mesmo em 
intercalações mais longas: esse não é um critério seguro. Talvez ele possa ser usado conjuntamente com um outro, que seria a posição da intercalação. como em (3): uma intercalação (que pode vir a ser considerada) digressiva presente no continuum.

(3) Redundância Seqüencial

(...) Redundâncias segmentais e redundâncias seqüenciais constituem, juntas, as condições de estrutura morfemática de uma lingua. ANTES DE PASSAR AO EXAME DESSAS CONDIÇÕES É NECESSÁRIO, POR UM MOMENTO, FAZER-SE UMA DIGRESSÃO PARA SE FALAR SOBRE O MORFEMA.

Morfemas: A morfologia estuda de que modo palavras são construídas a partir de constituintes menores. As partes componentes de palavras são morfemas (ex: raízes, radicais, prefixos, sufixos, terminações de plural, terminações de pretérito). (...).

O Léxico: O léxico de uma língua é uma lista dos morfemas da língua. Para cada morfema dão-se informações a respeito de seu significado, propriedades sintáticas (...).

Condições de Redundância Seqüencial

TENDO CONSIDERADO O MORFEMA E SEU PAPEL NO LEXICO, ESTAMOS PRONTOS PARA VOLTAR AGORA AO PROBLEMA ORIGINAL: A CONSTATAÇÃO DAS RESTRICOOES EM SEQÜÊNCIAS SEGMENTAIS. São examinados dois tipos de restrição, as condiçòes de estrutura silábicas as condições de se-entũo. (...). (Schane, 1975:65).

Nela, vemos, como em (1), a emergência do já-dito. evidenciando um outro nivel enunciativo. Tal intercalação pode ser experimentada como digressiva, não simplesmente por que seja mais cxtensa, nem porque verse sobre uma questão que, embora relacionada, constitui um sub-bloco mais especifico, nem mesmo porque esteja posta no contimumm textual. Ela pode ser digressiva pelas três razões conjuntamente e, ainda, pelo modo como o leitor a experiencie. Essa afirmação é plausível, porque o próprio autor da interposição adverte, com uma marcação característica (ele tem consciência de), que irá fazer uma digressào. () que ele faz, todavia e em verdade, é uma intercalação, conforme venho argumentando, cujo efeito pode figurar digressivo. 
Por tudo o que disse, considero uma intercalação não como algo dado, uma estratégia a priori, de modo que até mesmo a avaliação dos subtipos propostos dentro do critério de centração embora os conceba com categorias de análise e os defina de antemão não pode ser fechada e definitiva. Justifico: fundamento meu trabalho numa concepção de relevância que não se define previamente, e isso implica que a centração também não pode ser dada a priori; o tópico discursivo, muito menos. Mesmo considerando as cadeias isotópicas existentes (historicamente construídas), seria pouco produtivo sustentar que a relevância se resume a isso, pois é sempre possivel construir outros níveis de relevância; é possivel tornar relevantes aspectos aparentemente dispersos, não relacionados de antemão (a idéia de criatividade na linguagem não se resume apenas à geração de sentenças). Como bem afirma a LT, o processamento textual efetivase dialogicamente e on-line.

Esse postulado é imprescindivel para a compreensão de um fenômeno como as intercalações, pois acredito que elas fundam-se nas necessidades imediatas de organização textual, quando da emergência da heterogeneidade discursiva - de sujeitos e dizeres; num lugar em que se verifica o voltar-se ou antecipar-se do "sujeito- locutor" para comentar, por assim dizer, o que é dito, orientando, desse modo, a hicrarquia tópica e instituindo diferentes niveis de relevância. Por textualizar a heterogeneidade, o locutor configura uma aparente e necessária unidade textual e, nela, configura-se: faz-se ouvir e ver cntre as vozes que expressa e as posições que introduz: faz emergir () particular em meio à constitutiva dispersão discursiva. O locutor faz emergir, num trabalho em que se tem de articular no texto fragmentação dos sujeitos e dos dizeres, a atividade de um autor.

\section{Fechando o tema com a introdução da autoria}

Por meio do metadiscurso realizado nas intercalaçōes, o locutor caracteriza o trahalho da subjetividade, numa arena em que o conflito entre condicionamentos discursivos e "liberdade individual" faz emergir, por indicios, o particular; por meio do metadiscurso, configura-se, portanto, um trabalho de constituição de autoria. O texto é o lugar de constituição do conhecimento, como afirma a I T. e. por isso. defendo ser ele também o lugar de constitução e expressào de um autor (não simplesmente um locutor). Se os tertos são formas de cogniçäo social (...), são Iminulérorias whe aspectos de mundes 
(Antos, 1997), nada mais justo do que requerer para eles um autor. Assim, é plausivel defender que o trabalho do locutor converte a ação da subjetividade em autoria. Ao usar esse termo, remeto o leitor para a acepção que lhe fora dada por Possenti (2001), da qual tratarei em trabalhos seguintes.

Por ora, como anunciei, apenas introduzo a questão, relacionando-a às intercalações e ao metadiscurso, como forma de propor uma abordagem conjunta dos três conceitos. Esses, aliás, são os propósitos gerais do projeto que encampa a reflexão exposta, no qual proponho uma análise textual-discursiva das intercalações, por conceber a textualidade e a discursividade como dois princípios que se condicionam reciprocamente - dai a interface teórica. Uma abordagem assim possibilitará um tratamento satisfatório desta questão que vem, desde os mais antigos estudos, sendo relegada a um estatuto marginal. Espero poder contribuir também para uma necessária e urgente mudança de concepção sobre esse assunto no ensino, onde a questão é silenciada - quer pelo esquecimento, quer pela proibição declarada. Eis o que proponho.

\section{REFERÊNCIAS BIBLIOGRÁFICAS}

SANTOS, G. Textos como formas constitutivas do saber. Sobre algumas hipóteses para uma fundamentação da lingüistica de texto à base de uma teria evolucionária. In: ANTOS, G.; TIETZ,H. O futuro da lingüistica de texto. Tradiçòes, transformaçòes, tendências. Tubingen: Neimeyer. RGL 188. 1997.

AUTHIER-REVUZ, J. Heterogeneidade(s) enunciativas(s). Caderno de EstudosLingiüsticos. Campinas, n.19, 1990.

BAKHTIN, M. Marxismo e Filosofia dı Linguagem. São Paulo, Hucitec, 1979.

CHAROLLES, M. Introdução aos problemas de coerência nos textos: abordagem teórica e estudo das práticas pedagógicas. In: C. GALVEZ et al (org.). O texto, leitura e escrita. Campinas: Pontes, 1997.

DASCAL, M. \& KATRIEL., T. Digressions: a study in conversational coherence". In: J. PETOFI. Text w. Sentence, vol. 26, 1979. 
GIORA, R. Notes towards a theory of text and coherence. Poetics Today 6(4). 1985 .

GRICE, H. P. I.ogic and conversation. In: P. COLE \& J. L. MORGAN (orgs.). Syntax and Semantics 3: Speech Acts. Nova Iorque: Academic Press, 1975.

JUBRAN, C. C. S. et al. A organização tópica da conversação. In: ILARI, R. (org.). Gramática do Português Falado, vol. II, 1993.

KOCH, I. G.V. O texto e a construção dos sentidos. São Paulo: Contexto, 1997.

FUlgênCIO, L \& L.IBERATO. Y. A leitura na escola. São Paulo: Contexto. 1996.

MaIngueneAU, D. Novas tendências em Análise do discurso. Campinas: Pontes, 1997.

MOISÉS, M. Dicionário de Termos Literários. São Paulo: Cultrix, 1974.

Plebe, A \& EMANUEle, P. Manual de Retórica. São Paulo: Martins Fontes, 1992.

POSSENTI, S. O sujeito fora do arquivo. In: I. MAGALHÃES (org.). As multiplas facetas da linguagem. Brasilia: Editora UNB, 1998.

POSSENTI, S. Enunciação, autoria e estilo. Revista da Feeba, Departamento de Educação, Universidade do Estado da Bahia (UNEB), ano 10, n. 15, jun./jul. 2001. 